\title{
Dynamical Downscaling for Climate Projection with High-Resolution MRI AGCM-RCM
}

\author{
Akio KITOH \\ University of Tsukuba, Tsukuba, Japan \\ Tomoaki OSE, and Izuru TAKAYABU \\ Meteorological Research Institute, Tsukuba, Japan \\ (Manuscript received 9 November 2014, in final form 20 February 2015)
}

\begin{abstract}
High-resolution downscaling is vital to project climate extremes and their future changes by resolving fine topography reasonably well, which is a key to represent local climatology and impacts of weather extremes. A direct dynamical downscaling with a regional climate model (RCM) embedded within an atmosphere-ocean coupled general circulation model (AOGCM) is commonly used but is subject to systematic biases in their present-day simulations of AOGCM, which may cause unexpected effects on future projections and lead to difficult interpretation of climate change. In a high-resolution atmospheric general circulation model (AGCM)-RCM system, the present-day climate in AGCM is forced by observed sea surface temperature (SST) and sea-ice distribution. Then, the future climate is calculated with the "future" boundary conditions (SST and sea-ice), which are created by adding their future changes projected by AOGCM to the observed present-day values, besides the future radiative forcing. This system is one of methods to minimize the effects of such biases. A Meteorological Research Institute AGCM with $20-\mathrm{km}$ grids is successfully applied to project future changes in weather extremes such as tropical cyclones and rain systems that cause heavy rainfall and strong winds. Regional downscaling with 5-km mesh RCM is then performed over certain area to investigate local extreme rainfall events and their future changes. In this paper, we review various downscaling methods and try to rationalize a use of high-resolution AGCM-RCM system.
\end{abstract}

Keywords regional climate information; dynamical downscaling; GCM; RCM

\section{Introduction}

The fifth assessment report of the Intergovernmental Panel on Climate Change (IPCC) made the following assessments: observations of the climate system indicate that the warming is unequivocal and attribution studies show that human influence on warming is clear (IPCC 2013). Under this circum-

Corresponding author: Akio Kitoh, Faculty of Life and Environmental Sciences, University of Tsukuba, 1-1-1 Tennodai, Tsukuba, Ibaraki 305-8572, Japan

E-mail: kito.akio.ff@u.tsukuba.ac.jp

C 2016, Meteorological Society of Japan stance, reliable regional climate change projections are needed to make effective measures for adaptation and mitigation.

Development and improvement of general circulation models (GCMs) showed their increasing skill to represent global-scale climate and many important modes of climate variability (IPCC 2013). However, their skill for simulation of present-day climatology is not enough to discuss local features, and a grid size of atmosphere-ocean GCMs (AOGCMs) is typically of the order of $200 \mathrm{~km}$ and therefore cannot provide information at finer scales. Regional downscaling methods using dynamical models or empirical statis- 
tical downscaling can provide climate information at the smaller scales. Use of high-resolution dynamical models can add values through better representation of topography and coastlines, and also from improved representation of small-scale processes like convective precipitation.

Dynamical downscaling methods include nested regional climate models (RCMs) and high-resolution atmosphere-only general circulation models (AGCMs). Here, we discuss both methods focusing on the latter approach. For the short- and medium-range (up to 2 weeks) numerical weather predictions (NWPs), world centers are now using AGCMs with grid size around $15-30 \mathrm{~km}$. Some NWP centers use a regional model with a few $\mathrm{km}$ grids for veryshort-range forecasts. Due to increasing availability of high-performance computers, we are now capable to modify this NWP-type downscaling system for use in climate change projections. In Section 2, various dynamical downscaling methods are discussed. Section 3 shows the global high-resolution Meteorological research Institute (MRI)-AGCM, and Section 4 shows current projects for further dynamical downscaling by the non-hydrostatic regional climate model (NHRCM). Concluding remarks are given in Section 5.

\section{Dynamical downscaling methods}

There are two major approaches to dynamically downscale regional climate information from AOGCM. One is a nested regional climate model approach, in which large-scale atmospheric fields are supplied from AOGCM as lateral boundary conditions and sea surface temperature (SST) and sea ice as lower boundary conditions. Usually, 6-hourly atmospheric fields from AOGCM are used. Reliability of large-scale circulation of AOGCM determines the usefulness of downscaled fields.

The other is a high-resolution atmosphere-only GCM, in which land surface is usually included in AGCM and therefore predicted, but SST and sea ice information comes from the observation or AOGCM. Using observed SST and sea ice as lower boundary conditions in present-day simulation can avoid large bias existing in AOGCM present-day climate, but the absence of air-sea interaction within the system can cause distorted precipitation field and associated atmospheric circulation over some regions (Wang et al. 2005). How to prescribe the future boundary conditions will introduce another issue. Mizuta et al. (2008) introduced a method to derive future SST and sea ice for an AGCM time-slice experiment.

\subsection{Regional climate model}

a. Single-GCM/single-RCM

As a standard tool to dynamically downscale projections of future climate under a global warming world, a regional climate model is nested within a coarse resolution global AGCM or AOGCM. This approach was taken in Kurihara et al. (2005), and the results are used in Japan Meteorological Agency (JMA) Global Warming Projection Volume 6 (Japan Meteorological Agency 2005). The JMA has issued a series of publications entitled Global Warming Projection since 1996 in order to contribute to the impact assessment of global warming, the implementation of measures to mitigate and adapt to it, and the dissemination and enlightenment of scientific knowledge on the phenomenon.

Here, lateral and lower boundary conditions are taken from one AOGCM simulation, MRI Coupled General Circulation Model version 2 (MRI-CGCM2; Yukimoto et al. 2001) with T42 (280 km) atmospheric resolution. The historical simulation for 1981-2000 and the Special Report on Emission Scenario (SRES) A2 scenario simulation for 2081-2100 are used. Before applying to regional models, bias of SST is corrected to match the observations in the present-day simulation. The same bias correction was used in the future climate simulation.

In the regional climate change experiment, a double nesting method was used. A regional spectrum model with 60-km grid (RCM60), which covers eastern Asia, is first nested within the MRI-CGCM2. Finally, the projection of RCM60 gives the initial and boundary conditions of the $20-\mathrm{km}$ mesh model (RCM20). RCM60 and RCM20 were based on RSM (NPD/JMA 2002) that was used in operational NWP. In order to keep large-scale atmospheric fields of outer boundary conditions, a spectrum boundary coupling (SBC) technique (Kida et al. 1991; Sasaki et al. 1995, 2000) was applied in the atmosphere above $500 \mathrm{hPa}$. The SBC method adjusts the phase shift of disturbances between the outer coarse mesh model and the inner fine mesh model, and works to suppress the noise near the lateral boundary.

\section{b. Single-GCM/single-CRCM}

Information on climate change on ocean is also desirable. The Kuroshio is a northeastward flowing ocean current off the south coast of Japan. It is about $100 \mathrm{~km}$ wide and consists small- to meso-scale eddies. The AOGCMs are not able to well represent the Kuroshio because horizontal resolution of ocean model is coarse. 
In JMA Global Warming Projection Volume 7 (Japan Meteorological Agency 2008), the Coupled atmosphere-ocean Regional Climate Model (CRCM; Sasaki et al. 2006) developed by MRI was used to make detailed climate change projection around Japan. It couples the 20-km-mesh Regional Climate Model (RCM20; Sasaki et al. 2005) and the North Pacific Ocean General Circulation Model (NPOGCM; Sato et al. 2006). The NPOGCM has a domain from $15^{\circ} \mathrm{S}$ to $65^{\circ} \mathrm{N}$ and from $100^{\circ} \mathrm{E}$ to $75^{\circ} \mathrm{W}$ in the Pacific Ocean, with a horizontal resolution of $1 / 4^{\circ}$ longitude by $1 / 6^{\circ}$ latitudes. It is categorized as an eddy-permitting ocean model. The CRCM is forced by the MRI-CGCM2.3.2 (Yukimoto et al. 2006) under the SRES A1 and B1 scenarios. To calculate the atmospheric part, two-step nesting is applied due to the coarse grid size of the CGCM2.3.2. The RCM60 is nested within the CGCM2.3.2 results, and the RCM20 is nested within the RCM60 results. The SST calculated by the NPOGCM is used for the lower boundary condition of the RCM20, and the atmospheric surface data calculated by the RCM20 drive the NPOGCM. The data are exchanged between the NPOGCM and the RCM20 every hour during calculation.

This experiment projects future changes of Kuroshio warm current south of Japan. It is found that the volume transport and current position of the Kuroshio show no statistically significant trend with global warming. However, the projected maximum velocity of the Kuroshio shows a tendency to increase east of Japan by the end of the 21 st century.

\section{c. Multi-RCM/single-GCM}

Climate change projections always suffer from uncertainty. When information about future climate is provided, quantification of uncertainty is needed, and so ensemble simulations can be designed. One simple, single RCM by single GCM experiment could not clarify the uncertainty coming from model performance. Thus, a multi RCM experiment has been planned. For the first step, historical simulations have been performed. Analysis of the calculated results shows that the local scale climate is well reproduced (Iizumi et al. 2011; Ishizaki et al. 2012; Sasaki et al. 2012). However, it is also indicated that a systematic bias remains for some time even in ensemble mean results (Ishizaki et al. 2012; Christensen and Boberg 2012).

Adopting multi RCM downscaling could reduce the uncertainty of dynamical downscaling. There have been a series of studies that analyzed the results of multi RCM downscaling from the Model for
Interdisciplinary Research on Climate (MIROC)3.2(hires) AOGCM. From these analyses, bias in the typhoon track is reduced by taking ensemble mean of three RCMs (Iizuka et al. 2012), and the precipitation amount in the dominant precipitation area in the south-western side of the mountains in Japan in summer monsoon season increased remarkably at the end of the 21st century (Tsunematsu et al. 2013). They used three $20-\mathrm{km}$ mesh RCMs to downscale MIROC3.2(hires) twentieth century simulation (20C3M) (1981-2000) and SRES A1B scenario data (2081-2100) to investigate future changes in summertime precipitation amounts over Japan. Three RCMs used are the NHRCM at MRI, the Regional Atmospheric Modeling System (NRAMS) model at the National Research Institute for Earth Science and Disaster Prevention (NIED), and the Weather Research and Forecast (WRF) model at the University of Tsukuba (Kusaka et al. 2012). Verification study shows that the NHRCM and WRF tended to overestimate the June-July-August (JJA) mean precipitation in the Japanese islands, whereas the NRAMS mean biases were comparatively small. The model biases in the 95th percentile precipitation were underestimated in all RCMs. For future changes, they find noticeable increases in JJA mean precipitation in the west and south sides (windward sides) of the mountainous regions, especially in western Japan. This is related to increased southwesterly moisture flux coming from north-south atmospheric pressure gradients to the south of Japan, indicating importance of the topography and prevailing wind direction. As the latter mainly depends on GCM atmospheric fields, the choice of the driving GCM is critical for future climate projections.

Conversely, we should not forget the uncertainty coming from many RCMs when we apply the results to various impact study models. Iizumi et al. (2012) shows a large difference in the forage yielding estimation, when they use multi RCMs result as an input data. As some impact study models may be very sensitive to the change in meteorological condition, we need to use ensemble experiments results to make an assessment with probable range.

\section{d. Multi-GCM/single-RCM}

When we adopt a GCM as a parent model, the RCM characteristics depend strongly on the GCM performance, which is the limitation of using a single GCM as a parent model. Kusaka et al. (2012) used the 3-km mesh WRF model coupled with an urban canopy model to study heat stress changes in 
2070's for three metropolises in Japan, using three AOGCMs (MIROC3.2-medres, MRI-CGCM2.3.2a, and CSIRO-Mk3.0) under the SRES A1B scenario. They obtained an urban heat island intensity of $1.5^{\circ} \mathrm{C}$ in Tokyo at 2070s, which comparable to GCM temperature rises of $2.3^{\circ} \mathrm{C}$ (ranges between $1.7^{\circ} \mathrm{C}$ and $2.8^{\circ} \mathrm{C}$ ). In this way, relative uncertainty coming from GCM can be assessed compared to climate change signal.

\section{e. Multi-GCM/multi-RCM}

Inatsu et al. (2015) performed the experiments with three GCMs by three RCMs to evaluate the uncertainty in the future climate projection during summertime in Hokkaido, Japan. The GCM data come from MIROC3.2, the Max-Planck-Institut für Meteorologie (MPI) GCM, and the Community Climate System Model version 3 (CCSM3) at the time when global mean surface air temperature increases by $2 \mathrm{~K}$. For RCMs, NHRCM, WRF, and RSM are used. They find that uncertainty in temperature and precipitation mainly comes from the GCM imposed as the lateral boundary conditions.

A similar multi-GCM by multi-RCM experiment has been accomplished under the Ministry of Environment $(\mathrm{MoE})$ project with the help of the SOUSEI Program. Three AOGCMs are selected from Coupled Model Intercomparison Project phase 5 (CMIP5) models, considering accessibility to sub-daily data, i.e., the MIROC version 5 (MIROC5), MRI-CGCM3, and the Community Climate System Model version 4 (CCSM4). Four RCMs used are MRI-NHRCM, NIED-RAMS, Tsukuba-WRF, and the Atmosphere and Ocean Research Institute (AORI)-RSM. Resolution of RCMs is $20-\mathrm{km}$. Integrations are done for the present (1981-2000) with CMIP5 historical experiment, and the future (2081-2100) with CMIP5 Representative Concentration Pathway (RCP)-4.5 scenario experiment.

For the present day simulation, it is found that the temperature spread in winter is large both in GCM and RCM, which are related to the effect of topography and snow depth. However, the spread in summer temperature is large only in GCM, implying added value by using RCMs.

Here, selection of AOGCMs becomes a major issue. Mizuta et al. (2014) investigated future tropical SST changes obtained by 28 CMIP5 models under the RCP8.5 scenario. They classified into three clusters with different characteristics of tropical SST change patterns. Actually, MIROC5, MRI-CGCM3, and CCSM4 belong to different clusters, and thus the selection of these three models may be justified.
McSweeney et al. (2012) used a 2-stage process to select AOGCMs, on which downscaling is to be performed. First, they eliminate the models that fail to reproduce a realistic baseline climate. Second, they select a subset of models that span the range of plausible future projected changes in temperature and precipitation. Selected AOGCMs may be different from region to region because performance of AOGCM is usually not universal.

\section{f. Pseudo Global Warming (PGW) methods}

Simulated climates in an RCM are strongly influenced by larger scale forcing given by an AOGCM. Although sub-selection process can select better AOGCM in simulating baseline climate in their present-day simulation than others, they still suffer large model bias that exists in AOGCM for the present-day simulation. Figure 1 shows an example of simulated monthly mean sea-level pressure and surfaced wind in the Northwestern Pacific during July and August, compared to the Japanese 55-year Reanalysis (JRA55; Ebita et al. 2011) dataset. In this case, a bias in the subtropical high results in different wind directions from the real world. This would cause erroneous precipitation patterns particularly over the mountain areas in East Asia. To remedy such systematic biases of the forcing AOGCM, a pseudo global warming (PGW) method is proposed (Kimura and Kitoh 2007; Sato et al. 2007) and applied (Kawase et al. 2008, 2009; Hara et al. 2008; Matsumura and Sato 2011).

In the PGW downscaling method, the present climate is driven by objective analysis or reanalysis data. The boundary conditions in future climate are obtained by adding the monthly mean difference between the future and present climates simulated by AOGCM to the reanalysis data. The combined data are used as the boundary conditions for RCM simulations of the future climate. The forcing dataset generated by this process shows very similar spatial-temporal variations with the reanalysis data, but it contains large-scale changes of temperature, humidity, and winds as projected by AOGCM. Hence, the PGW downscaling method projects long-term trends but cannot estimate the projection of global warming onto such factors as storm frequency, storm intensity, and the positions of storm tracks.

The merits of the PGW method are to reduce influences of biases of AOGCM, to be able to replace each AOGCM climatological differences by multiAOGCM average, and to project well climate changes of mean values. Also sub-daily atmospheric data from AOGCM are not needed, because the PGW method 

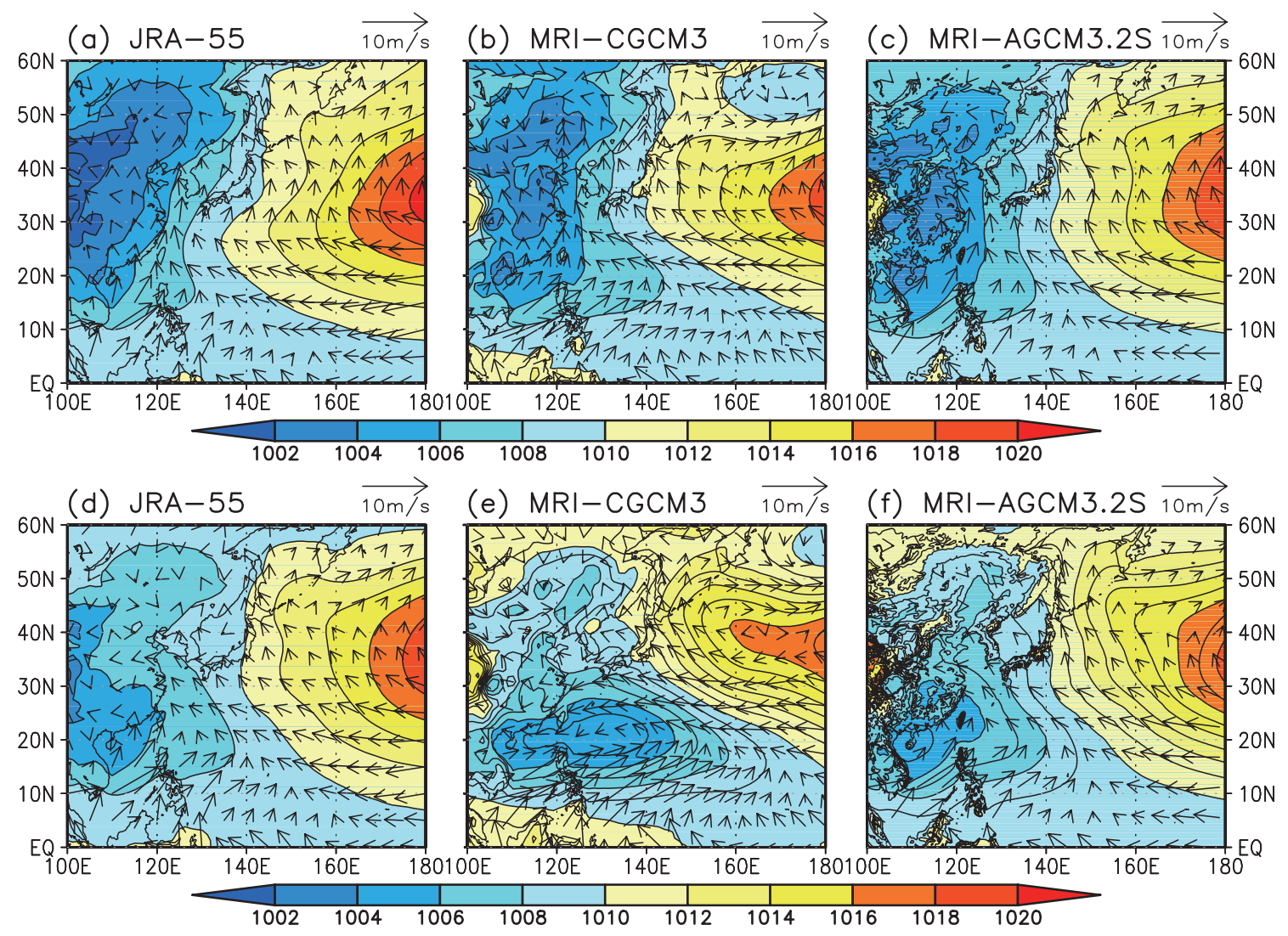

Fig. 1. Climatological mean sea-level pressure (shade and contour) and wind at $10 \mathrm{~m}$ above the surface for (a-c) July and (d-f) August. (a, d) JRA-55, (b-e) MRI-CGCM3, (c, f) MRI-AGCM3.2S.

requires only monthly mean atmospheric variables in AOGCM. Conversely, demerits of the original PGW method are that relative humidity is invariant, year-toyear variations are invariant, short-term disturbances are invariant, and treatment of uncertainty of AOGCM is not complete.

\section{g. Other bias correction methods}

Another approach is a bias correction of GCM mean field only for RCM downscaling. Done et al. (2013) and Bruyere et al. (2014) used a method to replace mean climatological field of AOGCM present-day simulation with reanalysis, retaining GCM-simulated synoptic and climate variability. This method allows synoptic and climate variability to change. By this method, they obtained reasonably reproduced hurricane characteristics in the North Atlantic in the present-day experiment. Xu and Yang (2012) made a correction both on mean and variance, in which the GCM climatological means and the amplitudes of interannual variations are adjusted based on the reanalysis before using them to drive RCM. Yoshimura and Kanamitsu (2013) proposed an incremental correction method for the dynamical downscaling of ensemble mean atmospheric fields, where a correction is made to one member in such a way that the seasonal mean is equal to that of the AOGCM ensemble mean.

Also some variants are proposed to remedy some of the demerits of the original PGW method. The PGW method does not treat climate changes in relative humidity, year-to-year variation, and short-term disturbances. Also treatment of uncertainty in GCM is not fully addressed. Wakazuki et al. (2013) developed the incremental dynamical downscaling and analysis system (InDDAS) that treats climate changes in relative humidity and year-to-year variations. In addition to the multi-model mean climatological differences between the present and future, they propose to use multi patterns derived from SVD using multi-GCM experiments, to estimate uncertainty of future climate projections. 
Bias correction is a kind of empirical statistical downscaling, and it needs information of present climate representation of the model. Thus, some kind of observation data is used as the validation data. In its procedure, it is assumed that the relation between the real world and model products does not change even in the future. Actually, the climate regime has been changing. This becomes a drawback of correcting bias for the model outputs.

\section{h. Past and existing projects using RCMs}

There are many international projects, handling multi RCMs (also multi GCMs in some of them), including the North American Regional Climate Change Assessment Program (NARCCAP) for North America (Mearns et al. 2009), the ENSEMBLES project for Europe (Hewitt and Griggs 2004; van der Linden and Mitchell 2009), and the Regional Climate Model Intercomparison Project (RMIP) for Asia (Fu et al. 2005). In these projects, they have performed dynamical downscaling for rather wide area, which covers a continent they will focus, by using $50 \mathrm{~km}$ grid RCMs. In NARCCAP and ENSEMBLES also, multi GCM by multi RCM approach has been tried. Now, the model calculations of all these projects have been completed, and a new framework call the Coordinated Regional climate Downscaling Experiment (CORDEX) was initiated (Giorgi et al. 2009), which have 16 regions local downscaling sub-frameworks. CORDEX covers all the regions of NARCCAP, ENSEMBLES, RMIP, and also many other regions. In Asian monsoon region, CORDEX-EA (East Asia), CORDEX-SA (South Asia), and CORDEX-SEA (Southeast Asia) are included.

\subsection{Global AGCM}

Global high-resolution AGCM can avoid lateral boundary conditions that introduce unnecessary interactions in RCMs. There are two approaches in high-resolution AGCM: uniform-grid high-resolution AGCM (e.g., Mizuta et al. 2006) and variable-resolution AGCM (e.g., McGregor et al. 2002). High-resolution models can reproduce small-scale structures such as tropical cyclones and localized phenomena associated with small-scale topography. Long-term integration of high-resolution AGCM over several decades requires good representations of physical structures of the small-scale phenomena, statistical climate of the small-scale phenomena, and global-scale climatology, in addition to computational resource.

Variable-resolution AGCM uses a regionally increased resolution on a target region, while a coarse resolution is used over the opposite side of the earth (e.g., McGregor et al. 2002). Generally variable-resolution AGCM uses the same physics scheme all over the world, which may cause a problem arising from different mesh size from region to region. Uniform high-resolution AGCM has no such problem, but needs substantial computational cost compared to variable-resolution AGCM. Although computation cost is large, uniform high-resolution AGCM yields high-resolution data throughout the world. In the next Section, we show such an example.

\section{MRI global high-resolution AGCM}

\subsection{Skill}

Mizuta et al. (2006) described the details of the 20-km mesh MRI-AGCM3.1 and evaluated its model climate against observations. The model shows reasonable quality in simulating climatic fields with good representation of regional-scale phenomena and local climate due to high horizontal resolution.

Kitoh and Kusunoki (2008) compared East Asian summer monsoon climate and Baiu rainfall simulated by a $20-\mathrm{km}$ mesh MRI-AGCM3.1 with a lower resolution $(180-\mathrm{km}$ mesh) version. They show that the 20-km mesh AGCM shows the superiority in simulating orographic rainfall by not only its location but also its amount. The Baiu frontal structure is also better simulated in the higher resolution model, with realistically strong Baiu rainfall.

Wang et al. (2011) evaluated annual variation of global monsoon precipitation of MRI-AGCM and 12 other AGCMs participated in the Atmospheric Model Intercomparison Project (AMIP-II). The 20-km mesh MRI-AGCM outperforms any individual AMIP II AGCMs and has comparable performance to 12-AMIP II model ensemble-mean simulations for global monsoon metrics.

Simulations of tropical cyclones (TCs) and their future changes are one of major issues in the experiments using the high-resolution MRI-AGCM because of their potential impacts on disasters. Murakami and Sugi (2010) investigated effects of model resolution on climatological features of TCs by comparing four resolution versions $(180,120,60$, and $20-\mathrm{km}$ mesh). The finest resolution $(20-\mathrm{km})$ showed the highest skills in terms of TC intensity and interannual and seasonal variations in TC genesis number. Resolutions of $60-\mathrm{km}$ mesh and finer showed a significant future increase in the frequency of intense TCs, whereas lower resolution versions coarser than $60-\mathrm{km}$ showed no such change, suggesting that $60-\mathrm{km}$ mesh is the critical resolution in projecting future change in the 
frequency of intense TCs.

Although MRI-AGCM3.1 has been reproducing observed climatological features reasonably and used for various climate change studies such as changes in tropical cyclones, the East Asian monsoon, extreme events, and blockings, there were still some biases that were necessary to be improved, including the geographical distribution of tropical cyclones and insufficient precipitation amounts over the Western Pacific.

A new version, MRI-AGCM3.2 has been developed (Mizuta et al. 2012) by introducing various new physics parameterizations including a new Yoshimura cumulus parameterization scheme (Yoshimura et al. 2015). The MRI-AGCM3.2 shows improvements in simulating heavy monthly-mean precipitation around the tropical Western Pacific, the global distribution of tropical cyclones, the seasonal march of East Asian summer monsoon, and blockings in the Pacific (Mizuta et al. 2012).

\subsection{Approach for future climate projections}

For the present climate simulation, we have used the observed interannually varying monthly mean SST and sea-ice concentration during 1979-2003. For the future climate, we have performed the timeslice 25-year simulation at the end of the 21 st century (2075-2099). The boundary SST data were prepared by superposing: (i) the trend in the multi-model ensemble (MME) of SST projected by CMIP3 or CMIP5 multi-model dataset, (ii) future change in MME of SST, and (iii) de-trended observed SST for the period 1979-2003. Details of the method are described in Mizuta et al. (2008).

Future change in MME of SST was evaluated by the difference between the 20th century simulations and future simulation under the SRES A1B emission scenario (CMIP3) for MRI-AGCM3.1 simulations or RCP scenarios (CMIP5) for MRI-AGCM3.2 simulations. The design retains observed year-to-year variability and El Niño and Southern Oscillation (ENSO) events in future climate, but with a higher mean and clear increasing trend in SST. Future sea-ice distribution is obtained in a similar fashion.

Mizuta et al. (2014) made a cluster analysis on tropical SST changes at the end of the 21st century projected by CMIP5 models under the RCP8.5 scenario. They obtained three distinguished tropical SST changes: Cluster 1 is characterized by a uniform warming over the tropics, while cluster 2 is dominated by a large warming over the subtropical North Pacific, and cluster 3 shows a large warming over the North
Indian Ocean and the northwestern Pacific. Associated with different tropical SST changes among clusters, characteristic precipitation responses are found over the monsoon regions especially in the Pacific Ocean and the Maritime Continent region (Mizuta et al. 2014). These three SST patterns together with ensemble mean SST have been used in the MRI-AGCM3.2 simulations with $20-\mathrm{km}$ and $60-\mathrm{km}$ grids.

\subsection{Study of future change in extreme events \\ a. Tropical cyclones}

In order to examine the impacts of global warming on TC activity, a model with a horizontally fine grid is necessary. Oouchi et al. (2006) were the first to use the $20-\mathrm{km}$ mesh AGCM to investigate possible changes in the frequency of wind intensity of TCs in a future warmed climate. They find the reduced TC frequency by approximately $30 \%$ in the warm-climate experiment compared to the present. Furthermore, the number of intense TCs increases. The global maximum surface wind speed for the most intense TC increases under the greenhouse warmed condition by $6.7 \mathrm{~m} \mathrm{~s}^{-1}$ or $13.7 \%$. Kitoh et al. (2009) reported a $40 \%-60 \%$ increase in precipitation and a $15 \%-20 \%$ increase in surface wind speeds within a $100-\mathrm{km}$ radius of the TC center at the end of the 21st century under the SRES A1B scenario.

The 20-km mesh MRI-AGCM3.2, compared to the previous version, improved representation of global distribution of observed TCs, and extremely strong TCs such as of categories 4 and 5, which were impossible to simulate by conventional global climate models (Murakami et al. 2012b). With this improved model, the future warming experiment projected the statistically significant increase in genesis frequency of TCs in the globe and both Southern and Northern Hemispheres. When viewed by region, projected genesis frequency statistically significantly and remarkably decreases in the Northwest Pacific and South Pacific and increases in the tropical central Pacific. Conversely, the genesis frequency of intense TCs will increase.

It is important to extract uncertainty in future projections. As TC consists of convective systems in which individual cumulus convection gathers together, a factor of the uncertainty lies in the cumulus convection scheme among physical processes. Also, as TC appears over oceans with warm SST, a difference in future changes in SST affects future changes in TC activity. In order to evaluate the uncertainty of the future projections of 
TC, Murakami et al. (2012a) used 12 types of multiphysics and SST ensemble experiments, using 3 different cumulus convection schemes and 4 different future change patterns of SSTs with use of the $60-\mathrm{km}$ mesh MRI-AGCM3.2. The occurrence frequency of TC was found to decrease in the West Pacific, South Pacific, and South Indian Ocean and increase in the Central Pacific around Hawaii, regardless of the experimental settings. Although the future changes in the genesis frequency of TC are generally consistent among the experiments in terms of the sign, the degree of the future changes varies among the experiments. An analysis of variance among the experiments show that the differences by the SST patterns largely contributed to the differences among the experiments, suggesting importance of projecting SST changes to reduce the uncertainty.

Other studies using MRI-AGCM3.1/3.2 include TC changes over North Atlantic (Murakami and Wang 2010; Raible et al. 2012; Murakami et al. 2014), the western North Pacific (Murakami et al. 2011), the North Indian Ocean (Murakami et al. 2013a), around Hawaii (Murakami et al. 2013b), and their long-term trend (Sugi and Yoshimura 2012).

\section{b. East Asian Monsoon}

East Asian summer monsoon climate is characterized both by Baiu-Meiyu rainfall and typhoons (tropical cyclones). The Baiu frontal structure is better reproduced in the $20-\mathrm{km}$ mesh model with stronger Baiu rainfall compared with that in lower resolution models (Kusunoki et al. 2006; Kitoh and Kusunoki 2008; Kusunoki and Mizuta 2008, 2012; Kusunoki et al. 2011).

The future climate simulation with the $20-\mathrm{km}$ mesh model shows an increase in precipitation over the Yangtze River valley in May through July (Meiyu), and over Japan in July (Baiu) at the end of the 21st century. The $20-\mathrm{km}$ mesh model and ensemble simulations by the $60-\mathrm{km}$ model consistently project that the termination of rainy season over Japan will delay until August in the future climate (Kusunoki et al. 2011).

Endo et al. (2012) discussed future changes and uncertainties in mean and extreme precipitation in Asia. Mean and extreme precipitation generally increase in South Asia and Southeast Asia, but their changes show marked differences among the ensemble projections. In contrast, in East Asia, northwestern China and Bangladesh, mean and extreme precipitation show consistent increases among the ensembles. Further investigation by analysis of vari- ance revealed that the uncertainty in the precipitation changes in South Asia and Southeast Asia comes mainly from differences in the cumulus schemes, with an exception in the Maritime Continent where the uncertainty originates mainly from the differences in the SST patterns used.

\section{c. Extreme rainfall}

High-resolution model is also important for studies of extreme precipitation. Using the $20-\mathrm{km}$ mesh MRI-AGCM3.1, Kamiguchi et al. (2006) showed that heavy precipitation was projected to increase substantially in South Asia, the Amazon, and West Africa, while a dry spell will increase in South Africa, southern Australia, and the Amazon at the end of the 21 st century, suggesting that the risk of water-related disasters will be higher in these regions. In the Asian monsoon region, heavy precipitation was projected to increase, notably in Bangladesh and in the Yangtze River basin due to the intensified convergence of water vapor flux in summer. Although changes in precipitation extremes are small and not significant over a large part of Japan, statistically significant increase in indices of heavy precipitation is found in western part of Japan and Hokkaido (Mizuta et al. 2005). Three-member $60-\mathrm{km}$ mesh model ensemble experiments fort the period 1872-2099 show that extreme precipitation indices over East Asia increase almost monotonically through the 21 st century (Kusunoki and Mizuta 2013). They show that the simple daily precipitation index (SDII) increased at $4.2 \%$ per degree of surface air temperature change, while the maximum 5-day precipitation total (R5d) increased at $5.5 \%$ per degree, both much larger than annual mean precipitation (2.2\% per degree).

\section{d. Blocking}

Atmospheric blocking is one of the important weather regimes in the weather and climate at midand high-latitudes and causes extremely high and low temperatures as well as extreme precipitation to the surrounding areas once it occurs and maintains. For example, the heat wave occurred in the summer of 2010 over eastern Europe to western Russia was caused by atmospheric blocking. Although numerical models have been known to underestimate the occurrence frequency of atmospheric blocking, a high-resolution AGCM is able to reproduce the occurrence frequency of blocking accurately (Matsueda et al. $2009,2010)$. At the end of the 21 st century, a decrease in the occurrence frequency in the Atlantic to Europe region $\left(30^{\circ} \mathrm{W}-50^{\circ} \mathrm{E}\right)$ is projected, while the occur- 


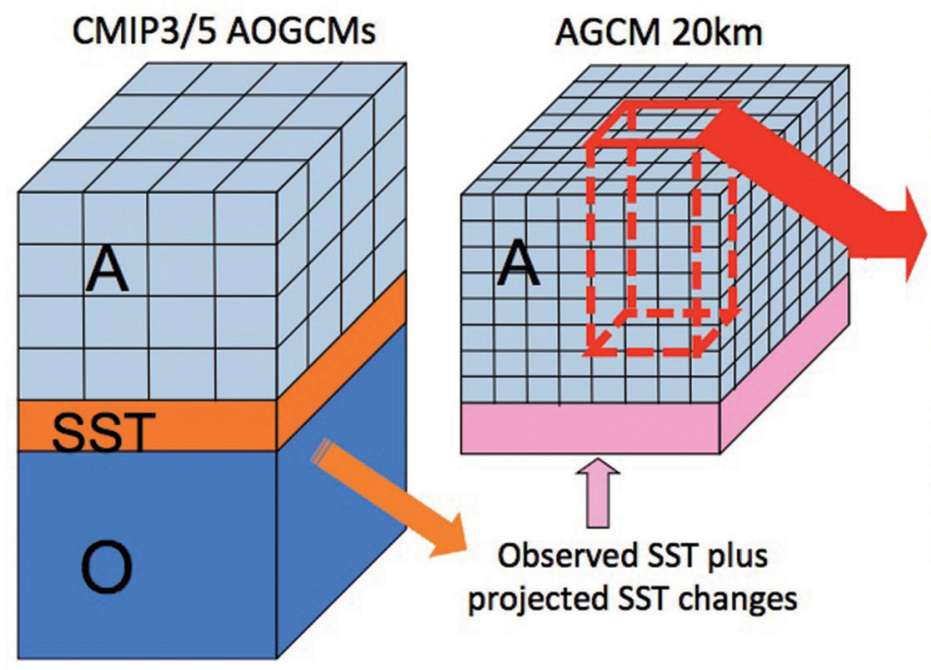

\section{Regional Climate Model NHRCM-5km NHRCM-2km}

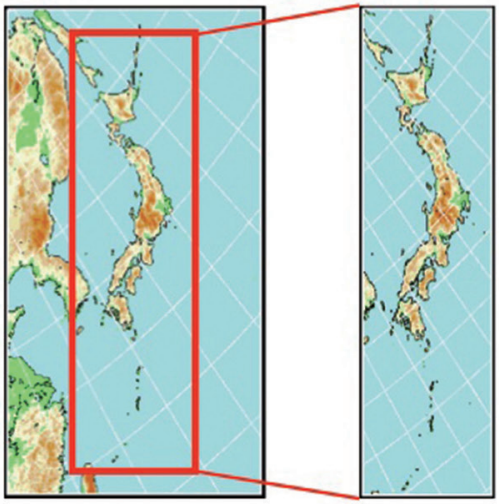

Fig. 2. A schematic of the high-resolution MRI AGCM-RCM system.

rence frequency in the Pacific region $\left(100^{\circ} \mathrm{E}-120^{\circ} \mathrm{W}\right)$ does not change.

\section{e. Extratropical cyclones}

In the mid-latitude region, disasters due to intense precipitation and strong winds are caused by extratropical cyclones, such as particularly strong cyclone activity and rapidly growing cyclones. Mizuta et al. (2011) examined future changes of the occurrence frequency of strong cyclones in the Northern Hemisphere in wintertime with the 20-km mesh MRI-AGCM3.1, and showed that the frequency increases on the polar side and downstream side (northeast side) of the areas where the present-day frequency is most high and the frequency decreases on the equatorial side and upstream side (southwest side). The average growth rate was intensifying on its upstream side (west side), where mid-troposphere jet streams intensify. Therefore, the jet streams, growth rate of cyclones, and the frequencies of strong cyclones all will increase on the polar side in the future warmed climate more than in the present day.

\section{f. Climate changes around the world}

One of the merits of using globally uniform high-resolution AGCM is availability of future projections anywhere in the world. There are many attempts to use MRI-AGCM3.1 future projections in various parts of the world, and those for MRI-AGCM3.2 will follow. Those regions include East Asia (Yun et al.
2008, 2012), India (Rajendran and Kitoh 2008; Rajendran et al. 2012, 2013; Krishnan et al. 2013), Bangladesh (Rahman et al. 2012, 2013), Tibetan Plateau (Arakawa and Kitoh 2012), Thailand (Champatong et al. 2013), the Mediterranean (Jin et al. 2010, 2011; Alpert et al. 2013), Middle East (Kitoh et al. 2008), the Caribbean (Hall et al. 2013; Pérez et al. 2014), Central America (Nakaegawa et al. 2013, 2014; Fábrega et al. 2013), and South America (Nakaegawa and Vergara 2010; Kitoh et al. 2011; Blazquez et al. 2012).

\section{Further dynamical downscaling by the MRI regional climate model (NHRCM)}

The time-slice experiment performed by a global uniform high-resolution AGCM can be used for further dynamical downscaling into a few $\mathrm{km}$ scales anywhere in the world. At MRI, a convection-permitting non-hydrostatic regional climate model (NHRCM) was used to downscale MRI-AGCM3.1/3.2 data for Japan. A schematic of the experiment is shown in Fig. 2. As described in Section 3.2, time-slice simulations with the MRI-AGCM are performed for the present and the future climate. The boundary conditions (SST and sea ice) come from either observations for the present or from hybrid of observations and AOGCM result (Mizuta et al. 2006). Downscaling with the $5-\mathrm{km}$ mesh NHRCM is then performed by nesting within the results of the $20-\mathrm{km}$ AGCM. Further downscaling with the $2-\mathrm{km}$ mesh 
NHRCM can be performed.

It is not our intention in this paper to review NHRCM and related results, as that will be found elsewhere (e.g., Wakazuki et al. 2007; Nakamura et al. 2008; Kanada et al. 2008, 2010a, 2010b, 2012, 2014; Nakano et al. 2010, 2011, 2012; Murata et al. 2012) and in this special issue. We rather limit ourselves to three projects recently conducted or being continuing, which uses the NHRCM embedded within the MRI high-resolution AGCM.

\subsection{KAKUSHIN Program (FY2007-2011) + SOUSEI Program (FY2012-2016)}

The KAKUSHIN Program was a 5-year (FY20072011) project "Innovative Program of Climate Change Projection for the 21st Century," using the Earth Simulator, funded by the Ministry of Education, Culture, Sports, Science, and Technology (MEXT). Under this KAKUSHIN Program, integration of the 5-km mesh NHRCM (NHRCM05) has been conducted from June to October by nesting within the results of the 10-year periods using the $20-\mathrm{km}$ MRI-AGCM3.1 for the present (1990-1999), near-future (2026-2035) and future climate (2086-2095) under the SRES A1B scenario (Table 1a; Kitoh et al. 2009).

The NHRCM05 has dramatically high performance in reproducing extreme indices of precipitation and enables discussion on realistic precipitation extremes (Kanada et al. 2008). It is found that the frequency of heavy precipitation will increase in the future for the hourly as well as daily precipitation over Japan. In particular, the strong hourly precipitation will increase even in near future: $99.9 \%$-ile value of hourly precipitation increases $7 \%$ in the near future and $21 \%$ at the end of the 21 st century (Kitoh et al. 2009).

Ensemble simulations of the NHRCM05 embedded within the 20-km mesh MRI-AGCM3.2 were performed under the SOUSEI Program, which is another 5-year (FY2012-2016) project "Program for Risk Information on Climate Change." Future climate projections with the $20-\mathrm{km}$ mesh MRI-AGCM3.2 were conducted using three SST patterns obtained by a cluster analysis of 28 CMIP5 RCP8.5 experiments (Mizuta et al. 2014) as well as 28 CMIP5 RCP8.5 ensemble means. Downscaling with NHRCM05 was performed for the 20 years at the present (1980-1999) and at the end of the 21st century (2076-2095) (Table 1c). Integration has just finished, and results will be reported soon. In the SOUSEI Program, further downscaling with the 2-km mesh NHRCM is planned.
4.2 JMA global warming projection volume 8 (2013)

As mentioned earlier, JMA issues information on global warming projection since 1996. In the latest Global Warming Projection Volume 8 (JMA 2013), future climate projections for the area around Japan based on the results of $5-\mathrm{km}$ mesh NHRCM embedded within the $20-\mathrm{km}$ mesh MRI-AGCM3.2 are shown.

In this experiment (Table 1b), GCM output was first downscaled by a $15-\mathrm{km}$ mesh NHRCM covering about $3,000 \mathrm{~km} \times 3,000 \mathrm{~km}$ region over Japan and the surrounding area. Then, a $5-\mathrm{km}$ mesh NHRCM was used to further downscale the Japan area with southwest to northeast oriented $661 \times 211$ grids, to efficiently cover the Japanese archipelago and reduce grid numbers. Calculations were made for three 20 -year periods at the present (1980-1999), the near future (2016-2035), and the future (2076-2095). One realization is available for each period. The SRES-A1B scenario was used in the MRI-AGCM3.2 simulation. The future SST anomalies are taken from 18 CMIP3 model ensemble means. Global Warming Projection Volume 8 (JMA 2013) reports projected climate changes in temperature, precipitation, snow depth and snowfall, relative humidity, global irradiance, and potential for the occurrence of severe weather events such as gusting winds and thunderstorms.

\subsection{MoE climate projections for adaptation (2014)}

Large-scale features in RCM simulations come from prescribed lateral boundary conditions, i.e., GCM simulations. Therefore, to tackle with uncertainty in regional climate projections, ensemble simulations with different GCM boundary conditions are necessary.

A 60-km mesh MRI-AGCM plus 20-km mesh NHRCM system is used for 18 -member ensemble climate change projections in the Ministry of the Environment Climate Projections for Adaptation. Experiments consist of a combination of three different SST anomalies, three cumulus parameterization schemes, and four different RCP scenarios (Table 1d). Future SST anomalies of CMIP5 models under the RCP2.6, RCP4.5, RCP6.0, and RCP8.5 scenarios are used to make three SST clusters at the end of the 21st century. These SST anomalies are added to the present-day observed SST with a method similar to Mizuta et al. (2008). Resultant SST clusters are discussed in Mizuta et al. (2014). Therefore, there are 12 members (three SST clusters times four scenarios), which use the standard MRI-AGCM3.2 
Table 1. List of experiments performed by (a) KAKUSHIN program, (b) JMA Global Warming Projection Volume 8, (c) SOUSEI program, and (d) MoE adaptation program. Suffix S and H of model version denotes 20-km mesh and 60-km mesh, respectively. YS, KF, and AS denotes Yoshimura scheme, Kain-Fritch scheme, and Arakawa-Schubert scheme in the cumulus parameterization, respectively.

\begin{tabular}{|c|c|c|c|c|c|c|c|}
\hline & \multicolumn{5}{|l|}{ GCM } & \multicolumn{2}{|l|}{$\mathrm{RCM}$} \\
\hline & version & resolution & scenario & period & SST & resolution & period \\
\hline \multirow[t]{3}{*}{ (a) KAKUSHIN } & MRI-AGCM3.1S (AS) & $20 \mathrm{~km}$ & present & $1979-2003$ & HadISST1.1 & $5 \mathrm{~km}$ & 1990-1999 \\
\hline & & & SRES A1B & 2016-2039 & CMIP3 MME & $5 \mathrm{~km}$ & $2026-2035$ \\
\hline & & & SRES A1B & 2075-2099 & CMIP3 MME & $5 \mathrm{~km}$ & 2086-2095 \\
\hline \multirow[t]{3}{*}{ (b) JMA Vol. 8} & MRI-AGCM3.2S (YS) & $20 \mathrm{~km}$ & present & $1979-2003$ & HadISST1.1 & $15 \mathrm{~km}+5 \mathrm{~km}$ & 1980-1999 \\
\hline & & & SRES A1B & 2016-2039 & CMIP3 MME & $15 \mathrm{~km}+5 \mathrm{~km}$ & 2016-2035 \\
\hline & & & SRES A1B & 2075-2099 & CMIP3 MME & $15 \mathrm{~km}+5 \mathrm{~km}$ & 2076-2095 \\
\hline \multirow[t]{5}{*}{ (c) SOUSEI } & MRI-AGCM3.2S (YS) & $20 \mathrm{~km}$ & present & $1979-2003$ & HadISST1.1 & $5 \mathrm{~km}$ & 1980-1999 \\
\hline & & & RCP8.5 & 2075-2099 & CMIP5 MME & $5 \mathrm{~km}$ & 2076-2095 \\
\hline & & & RCP8.5 & 2075-2099 & CMIP5 cluster 1 & $5 \mathrm{~km}$ & 2076-2095 \\
\hline & & & RCP8.5 & 2075-2099 & CMIP5 cluster2 & $5 \mathrm{~km}$ & 2076-2095 \\
\hline & & & RCP8.5 & 2075-2099 & CMIP5 cluster3 & $5 \mathrm{~km}$ & 2076-2095 \\
\hline \multirow[t]{21}{*}{ (d) MoE adapt } & MRI-AGCM3.2H (YS) & $60 \mathrm{~km}$ & present & 1984-2004 & HadISST1.1 & $20 \mathrm{~km}$ & 1984-2004 \\
\hline & MRI-AGCM3.2H (KF) & & present & 1984-2004 & HadISST1.1 & $20 \mathrm{~km}$ & 1984-2004 \\
\hline & MRI-AGCM3.2H (AS) & & present & 1984-2004 & HadISST1.1 & $20 \mathrm{~km}$ & 1984-2004 \\
\hline & MRI-AGCM3.2H (YS) & & RCP8.5 & $2080-2100$ & CMIP5 cluster 1 & $20 \mathrm{~km}$ & $2080-2100$ \\
\hline & MRI-AGCM3.2H (YS) & & RCP8.5 & $2080-2100$ & CMIP5 cluster2 & $20 \mathrm{~km}$ & $2080-2100$ \\
\hline & MRI-AGCM3.2H (YS) & & RCP8.5 & $2080-2100$ & CMIP5 cluster3 & $20 \mathrm{~km}$ & $2080-2100$ \\
\hline & MRI-AGCM3.2H (KF) & & RCP8.5 & $2080-2100$ & CMIP5 cluster 1 & $20 \mathrm{~km}$ & $2080-2100$ \\
\hline & MRI-AGCM3.2H (KF) & & RCP8.5 & $2080-2100$ & CMIP5 cluster2 & $20 \mathrm{~km}$ & $2080-2100$ \\
\hline & MRI-AGCM3.2H (KF) & & RCP8.5 & $2080-2100$ & CMIP5 cluster3 & $20 \mathrm{~km}$ & $2080-2100$ \\
\hline & MRI-AGCM3.2H (AS) & & RCP8.5 & $2080-2100$ & CMIP5 cluster1 & $20 \mathrm{~km}$ & $2080-2100$ \\
\hline & MRI-AGCM3.2H (AS) & & RCP8.5 & $2080-2100$ & CMIP5 cluster2 & $20 \mathrm{~km}$ & $2080-2100$ \\
\hline & MRI-AGCM3.2H (AS) & & RCP8.5 & $2080-2100$ & CMIP5 cluster3 & $20 \mathrm{~km}$ & $2080-2100$ \\
\hline & MRI-AGCM3.2H (YS) & & RCP6.0 & $2080-2100$ & CMIP5 cluster 1 & $20 \mathrm{~km}$ & $2080-2100$ \\
\hline & MRI-AGCM3.2H (YS) & & RCP6.0 & $2080-2100$ & CMIP5 cluster2 & $20 \mathrm{~km}$ & $2080-2100$ \\
\hline & MRI-AGCM3.2H (YS) & & RCP6.0 & $2080-2100$ & CMIP5 cluster3 & $20 \mathrm{~km}$ & $2080-2100$ \\
\hline & MRI-AGCM3.2H (YS) & & $\mathrm{RCP} 4.5$ & $2080-2100$ & CMIP5 cluster 1 & $20 \mathrm{~km}$ & $2080-2100$ \\
\hline & MRI-AGCM3.2H (YS) & & $\mathrm{RCP} 4.5$ & $2080-2100$ & CMIP5 cluster2 & $20 \mathrm{~km}$ & $2080-2100$ \\
\hline & MRI-AGCM3.2H (YS) & & $\mathrm{RCP} 4.5$ & $2080-2100$ & CMIP5 cluster3 & $20 \mathrm{~km}$ & $2080-2100$ \\
\hline & MRI-AGCM3.2H (YS) & & $\mathrm{RCP} 2.6$ & $2080-2100$ & CMIP5 cluster1 & $20 \mathrm{~km}$ & $2080-2100$ \\
\hline & MRI-AGCM3.2H (YS) & & $\mathrm{RCP} 2.6$ & $2080-2100$ & CMIP5 cluster2 & $20 \mathrm{~km}$ & $2080-2100$ \\
\hline & MRI-AGCM3.2H (YS) & & RCP2.6 & $2080-2100$ & CMIP5 cluster3 & $20 \mathrm{~km}$ & $2080-2100$ \\
\hline
\end{tabular}

with the Yoshimura scheme. For the RCP8.5 scenario, we also performed two different cumulus schemes, i.e., Kain-Fritch scheme (Kain and Fritsch 1990) and Arakawa-Schubert scheme (Randall and Pan 1993) (additional two schemes with three different SST), totaling in 18 members. The target is a 20 -year period of 2080-2100. For the present-day simulation (19842004), three simulations with different cumulus schemes are performed.

Some results based on these data are found in this special issue. Results will be used for adaptation planning in the Government of Japan.

\section{Concluding remarks}

Regional climate information is needed not only for impact study but also for planning of adaptation for climate change in various sectors. Because regional climate is often related to small-scale topography, land-sea distribution, land cover and land use, some means are used to downscale global-scale climate change projections into horizontally high-resolution climate change information. As climate is aggregated weather, models should reasonably simulate daily weather. For example, heavy rainfall is often comes 
from small-scale phenomena. Therefore, high-resolution climate model becomes candidate for such a purpose.

Global high-resolution AGCM simulation is one of good choices for downscaling by avoiding SST bias that exists in AOGCM. This method can obtain good performance in the present-day climate by prescribing SST. Also in the future climate projection, SST bias can be minimized by using the observed present-day interannually varying SST plus CMIP5 ensemble mean future SST changes or others. This method has been extensively used with the $20-\mathrm{km}$ mesh MRI-AGCM, and also being planned or used in other modeling centers. For example, Haarsma et al. (2013) used the 25-km mesh European Centre for Medium-Range Weather Forecasts numerical weather prediction model to investigate hurricane occurrence in the North Atlantic and found more hurricanes hitting Western Europe in a warmed climate.

As the model is global, projected data are available anywhere in the world. These data obtained by the $20-\mathrm{km}$ mesh MRI-AGCM is already used for various application studies on disaster prevention in collaboration with other national institutes and universities, and helping climate change studies through international collaborations.

Further downscaling with a few $\mathrm{km}$ cloud-resolving RCM was applied to investigate local extreme weather events such as heat waves from foehn and heavy rainfall. Because cloud-resolving models have potential to better simulate extreme weather phenomena than GCMs, use of RCMs can reduce uncertainty originating from cumulus parameterizations used in GCMs. In addition to that, recent RCMs have incorporated urban climate model. Dynamical downscaling by RCMs using the time-sliced, high-resolution AGCM can be applied to any region in the world.

\section{Acknowledgments}

This work was supported by the SOUSEI Program of the Ministry of Education, Culture, Sports, Science, and Technology (MEXT) of Japan. We acknowledge the reviewer's comments that helped us to revise the manuscript.

\section{References}

Alpert, P., D. Hemmings, F. Jin, G. Kay, A. Kitoh, and A. Mariotti, 2013: The Hydrological Cycle of the Mediterranean. Navarra A., and L. Tubiana (eds.) Regional Assessment of Climate Change in the Mediterranean. Springer Netherlands, 201-239.
Arakawa, O., and A. Kitoh, 2012: Elevation dependency of summertime precipitation and its change by global warming over the Tibetan Plateau and the surroundings simulated by a $60-\mathrm{km}$-mesh atmospheric general circulation model. J. Meteor. Soc. Japan, 90A, 151-165.

Blázquez, J., M. N. Nuñez, and S. Kusunoki, 2012: Climate projections and uncertainties over South America from MRI/JMA global model experiments. Atmos. Climate Sci., 2, 381-400.

Bruyere, C. L., J. M. Done, G. J. Holland, and S. Fredrick, 2014: Bias corrections of global models for regional climate simulations of high-impact weather. Climate Dyn., 43, 1847-1856.

Champathong, A., D. Komori, M. Kiguchi, T. Sukkhapunnapan, T. Nakaegawa, and T. Oki, 2013: Future projection of mean river discharge climatology for the Chao Phraya River basin. Hydrol. Res. Lett., 7, 36-41.

Christensen, J. H., and F. Boberg, 2012: Temperature dependent climate projection deficiencies in CMIP5 models. Geophys. Res. Lett., 39, L24705, doi:10.1029/2012GL053650.

Done, J. M., G. J. Holland, C. L. Bruyere, L. R. Leung, and A. Suzuki-Parker, 2013: Modeling high-impact weather and climate: lessons from a tropical cyclone perspective. Climate Change, 129, 381-395.

Ebita, A., S. Kobayashi, Y. Ota, M. Moriya, R. Kumabe, K. Onogi, Y. Harada, S. Yasui, K. Miyaoka, K. Takahashi, H. Kamahori, C. Kobayashi, H. Endo, M. Soma, Y. Oikawa, and T. Ishimizu, 2011: The Japanese 55-year reanalysis "JRA-55": An interim report. SOLA, 7, 149-152.

Endo, H., A. Kitoh, T. Ose, R. Mizuta, and S. Kusunoki, 2012: Future changes and uncertainties in Asian precipitation simulated by multi-physics and multi-sea surface temperature ensemble experiments with high-resolution Meteorological Research Institute atmospheric general circulation models (MRI-AGCMs). J. Geophys. Res., 117, D16118, doi:10.1029/2012JD017874.

Fábrega, J., T. Nakaegawa, R. Pinzón, K. Nakayama, O. Arakawa, and SOUSEI Theme-C modeling group, 2013: Hydroclimate projections for Panama in the 21st Century. Hydrol. Res. Lett., 7, 23-29.

Fu, C., S. Wang, Z. Xiong, W. J. Gutowski, D.-K. Lee, J. L. McGregor, Y. Sato, H. Kato, J.-W. Kim, and M.-S. Suh, 2005: Regional climate model intercomparison project for Asia. Bull. Amer. Meteor. Soc., 86, 257-266.

Giorgi, F., C. Jones, and G. R. Asrar, 2009: Addressing climate information needs at the regional level: the CORDEX framework. WMO Bull., 58, 175-183.

Haarsma, R. J., W. Hazeleger, C. Severijns, H. de Vries, A. Sterl, R. Bintanja, G. J. van Oldenborgh, and H. W. van den Brink, 2013: More hurricanes to hit western Europe due to global warming. Geophys. Res. Lett., 
40, doi:10.1002/grl.50360.

Hall, T. C., A. M. Sealy, T. S. Stephenson, S. Kusunoki, M. A. Taylor, A. A. Chen, and A. Kitoh, 2013: Future climate of the Caribbean from a super-high-resolution atmospheric general circulation model. Theor. Appl. Climatol., 113, 271-287.

Hara, M. T., T. Yoshikane, H. Kawase, and F. Kimura, 2008: Estimation of the impact of global warming on snow depth in Japan by the pseudo-global-warming method. Hydrol. Res. Lett., 2, 61-64.

Hewitt, C. D., and D. J. Griggs, 2004: Ensembles-based predictions of climate changes and their impacts. Eos. Trans. Amer. Geophys. Union, 85, 566-567.

Iizuka, S., K. Dairaku, W. Sasaki, S. A. Adachi, N. N. Ishizaki, H. Kusaka, and I. Takayabu, 2012: Assessment of ocean surface winds and tropical cyclones around Japan by RCMs. J. Meteor. Soc. Japan, 90B, 91-102.

Iizumi, T., M. Nishimori, K. Dairaku, S. A. Adachi, and M. Yokozawa, 2011: Evaluation and intercomparison of downscaled daily precipitation indices over Japan in present-day climate: Strengths and weaknesses of dynamical and bias correction-type statistical downscaling methods. J. Geophys. Res., 116, D01111, doi:10.1029/2010JD014513.

Iizumi, T., F. Uno, and M. Nishimori, 2012: Climate downscaling as a source of uncertainty in projecting local climate change impacts. J. Meteor. Soc. Japan, 90B, 83-90.

Inatsu, M., T. Sato, T. J. Yamada, R. Kuno, S. Sugimoto, M. A. Farukh, Y. N. Pokhrel, and S. Kure, 2015: Multi-GCM by multi-RAM experiments for dynamical downscaling on summertime climate change in Hokkaido. Atmos. Sci. Lett., doi:10.1002/as12.557.

IPCC, 2013: Climate Change 2013: The Physical Science Basis. Contribution of Working Group I to the Fifth Assessment Report of the Intergovernmental Panel on Climate Change. Stocker, T. F., D. Qin, G.-K. Plattner, M. Tignor, S. K. Allen, J. Boschung, A. Nauels, Y. Xia, V. Bex, and P. M. Midgley (eds.), Cambridge University Press, Cambridge, United Kingdom and New York, NY, USA, 1535 pp.

Ishizaki, N. N., I. Takayabu, M. Oh'Izumi, H. Sasaki, K. Dairaku, S. Iizuka, F. Kimura, H. Kusaka, S. A. Adachi, K. Kurihara, K. Murazaki, and K. Tanaka, 2012: Improved performance of simulated Japanese climate with a multi-model ensemble. J. Meteor. Soc. Japan, 90, 235-254.

Japan Meteorological Agency, 2005: Global Warming Projection Vol. 6. 58 pp (in Japanese). [Available at http://ds.data.jma.go.jp/tcc/tcc/products/gwp/gwp6/ index.html.]

Japan Meteorological Agency, 2008: Global Warming Projection Vol. 7. 59 pp (in Japanese). [Available at http://ds.data.jma.go.jp/tcc/tcc/products/gwp/gwp7/ index-e.html.]

Japan Meteorological Agency, 2013: Global Warming
Projection Vol. 8. 145 pp (in Japanese). [Available at http://ds.data.jma.go.jp/tcc/tcc/products/gwp/gwp8/ index.html.]

Jin, F., A. Kitoh, and P. Alpert, 2010: Water cycle changes over the Mediterranean: a comparison study of a super-high-resolution global model with CMIP3. Phil. Trans. R. Soc. A, 368, 5137-5149.

Jin, F., A. Kitoh, and P. Alpert, 2011: Climatological relationships among the moisture budget components and rainfall amounts over the Mediterranean based on a super-high-resolution climate model. J. Geophys. Res., 116, D09102, doi:10.1029/2010JD014021.

Kain, J. S., and J. M. Fritsch, 1990: A one-dimensional entraining/detraining plume model and its application in convective parameterization. J. Atmos. Sci., 47, 2784-2802.

Kamiguchi, K., A. Kitoh, T. Uchiyama, R. Mizuta, and A. Noda, 2006: Changes in precipitation-based extremes indices due to global warming projected by a global 20-km-mesh atmospheric model. SOLA, 2, 64-67.

Kanada, S., M. Nakano, S. Hayashi, T. Kato, M. Nakamura, K. Kurihara, and A. Kitoh, 2008: Reproducibility of maximum daily precipitation amount over Japan by a high-resolution non-hydrostatic model. SOLA, 4, 105-108.

Kanada, S., M. Nakano, and T. Kato, 2010a: Changes in mean atmospheric structures around Japan during July due to global warming in regional climate experiments using a cloud-system resolving model. Hydrol. Res. Lett., 4, 11-14.

Kanada, S., M. Nakano, and T. Kato, 2010b: Climatological characteristics of daily precipitation over Japan in the Kakushin regional climate experiments using a non-hydrostatic 5-km-mesh model: Comparison with an outer global 20-km-mesh atmospheric climate model. SOLA, 6, 117-120.

Kanada, S., M. Nakano, and T. Kato, 2012: Projections of future changes in precipitation and the vertical structure of the frontal zone during the Baiu Season in the vicinity of Japan using a 5-km-mesh regional climate model. J. Meteor. Soc. Japan, 90A, 65-86.

Kanada, S., H. Tsuguti, T. Kato, and F. Fujibe, 2014: Diurnal Variation of Precipitation around Western Japan during the Warm Season. SOLA, 10, 72-77.

Kawase, H., T. Yoshikane, M. Hara, B. Ailikun, F. Kimura, and T. Yasunari, 2008: Downscaling of the climatic change in the rainband in East Asia by a pseudo climate simulation method. SOLA, 4, 73-76.

Kawase, H., T. Yoshikane, M. Hara, B. Ailikun, F. Kimura, T. Yasunari, T. Inoue, and H. Ueda, 2009: Intermodel variability of future changes in the Baiu rainband estimated by the pseudo global warming downscaling method. J. Geophys. Res., 114, D24110, doi:10.1029/2009JD011803.

Kida, H., T. Koide, H. Sasaki, and M. Chiba, 1991: A new approach to coupling a limited area model with a 
GCM for regional climate simulations. J. Meteor. Soc. Japan, 69, 723-728.

Kimura, F., and A. Kitoh, 2007: Downscaling by pseudo global warming method. The Final Report of ICCAP. 43-46.

Kitoh, A., and S. Kusunoki, 2008: East Asian summer monsoon simulation by a $20-\mathrm{km}$ mesh AGCM. Climate Dyn., 31, 389-401.

Kitoh, A., A. Yatagai, and P. Alpert, 2008: First super-high-resolution model projection that the ancient "Fertile Crescent" will disappear in this century. Hydrol. Res. Lett., 2, 1-4.

Kitoh, A., T. Ose, K. Kurihara, S. Kusunoki, M. Sugi, and KAKUSHIN Team-3 Modeling Group, 2009: Projection of changes in future weather extremes using super-high-resolution global and regional atmospheric models in the KAKUSHIN Program: Results of preliminary experiments. Hydrol. Res. Lett., 3, 49-53.

Kitoh, A., S. Kusunoki, and T. Nakaegawa, 2011: Climate change projections over South America in the late 21 st century with the 20 and $60 \mathrm{~km}$ mesh Meteorological Research Institute atmospheric general circulation model (MRI-AGCM). J. Geophys. Res., 116, D06105, doi:10.1029/2010JD014920.

Krishnan, R., T. P. Sabin, D. C. Ayantika, A. Kitoh, M. Sugi, H. Murakami, A. G. Turner, J. M. Slingo, and K. Rajendran, 2013: Will the South Asian monsoon overturning circulation stabilize any further? Climate Dyn., 40, 187-211.

Kurihara, K., K. Ishihara, H. Sasaki, Y. Fukuyama, H. Saitou, I. Takayabu, K. Murazaki, Y. Sato, S. Yukimoto, and A. Noda, 2005: Projection of climatic change over Japan due to global warming by High-Resolution Regional Climate Model in MRI. SOLA, 1, 97-100.

Kusaka, H., M. Hara, and Y. Takane, 2012: Urban climate projection by the WRF model at 3-km horizontal grid increment: Dynamical downscaling and predicting heat stress in the 2070's August for Tokyo, Osaka, and Nagoya metropolises. J. Meteor. Soc. Japan, 90B, 47-63.

Kusunoki, S., and R. Mizuta, 2008: Future changes in the Baiu rain rand projected by a $20-\mathrm{km}$ mesh global atmospheric model: sea surface temperature dependence. SOLA, 4, 85-88.

Kusunoki, S., and R. Mizuta, 2012: Comparison of near future (2015-2039) changes in the East Asian rain band with future (2075-2099) changes projected by global atmospheric models with $20-\mathrm{km}$ and $60-\mathrm{km}$ grid size. SOLA, 8, 73-76.

Kusunoki, S., and R. Mizuta, 2013: Changes in precipitation intensity over East Asia during the 20th and 21st centuries simulated by a global atmospheric model with a $60 \mathrm{~km}$ grid size. J. Geophys. Res. Atmos., 118, 11007-11016.

Kusunoki, S., J. Yoshimura, H. Yoshimura, A. Noda, K.
Oouchi, and R. Mizuta, 2006: Change of Baiu rain band in global warming projection by an atmospheric general circulation model with a $20-\mathrm{km}$ grid size. $J$. Meteor. Soc. Japan, 84, 581-611.

Kusunoki, S., R. Mizuta, and M. Matsueda, 2011: Future changes in the East Asian rain band projected by global atmospheric models with $20-\mathrm{km}$ and $60-\mathrm{km}$ grid size. Climate Dyn., 37, 2481-2493.

Matsueda, M., R. Mizuta, and S. Kusunoki, 2009: Future change in wintertime atmospheric blocking simulated using a 20-km-mesh atmospheric global circulation model. J. Geophys. Res., 114, D12114, doi:10.1029/2009JD011919.

Matsueda, M., H. Endo, and R. Mizuta, 2010: Future change in Southern Hemisphere summertime and wintertime atmospheric blockings simulated using a 20-km-mesh AGCM. Geophys. Res. Lett., 37, L02803, doi:10.1029/2009GL041758.

Matsumura, S., and T. Sato, 2011: Snow/ice and cloud responses to future climate change. SOLA, 7, 205-208.

McGregor, J. L., K. C. Nguyen, and J. J. Katzfey, 2002: Regional climate simulations using a stretched-grid global model. Research Activities in Atmospheric and Oceanic Modelling Report 32, Ritchie, H. (ed.), World Meteorological Organisation, Geneva, 15-16 pp.

McSweeney, C. F., R. G. Jones, and B. B. B. Booth, 2012: Selecting ensemble members to provide regional climate change information. J. Climate, 25, 71007121.

Mearns, L. O., W. J. Gutowski, R. Jones, R. Leung, S. McGinnis, A. Nunes, and Y. Qian, 2009: A regional climate change assessment program for North America. Eos, Trans. Amer. Geophys. Union, 90, 311-312.

Mizuta, R., T. Uchiyama, K. Kamiguchi, A. Kitoh, and A. Noda, 2005: Changes in extremes indices over Japan due to global warming projected by a global $20-\mathrm{km}-$ mesh atmospheric model. SOLA, 1, 153-156.

Mizuta, R., K. Oouchi, H. Yoshimura, A. Noda, K. Katayama, S. Yukimoto, M. Hosaka, S. Kusunoki, H. Kawai, and M. Nakagawa, 2006: 20-km-mesh global climate simulations using JMA-GSM model -Mean climate states-. J. Meteor. Soc. Japan, 84, 165-185.

Mizuta, R., Y. Adachi, S. Yukimoto, and S. Kusunoki, 2008: Estimation of future distribution of sea surface temperature and sea ice using CMIP3 multi-model ensemble mean. Tech. Rep. Meteorological Research Institute, 56, $28 \mathrm{pp}$.

Mizuta, R., M. Matsueda, H. Endo, and S. Yukimoto, 2011: Future change in extratropical cyclones associated with change in the upper troposphere. J. Climate, 24, 6456-6470.

Mizuta, R., H. Yoshimura, H. Murakami, M. Matsueda, H. Endo, T. Ose, K. Kamiguchi, M. Hosaka, M. Sugi, S. 
Yukimoto, S. Kusunoki, and A. Kitoh, 2012: Climate simulations using MRI-AGCM3.2 with $20-\mathrm{km}$ grid. $J$. Meteor. Soc. Japan, 90A, 233-258.

Mizuta, R., O. Arakawa, T. Ose, S. Kusunoki, H. Endo, and A. Kitoh, 2014: Classification of CMIP5 future climate responses by the tropical sea surface temperature changes. SOLA, 10, 167-171.

Murakami, H., and M. Sugi, 2010: Effect of model resolution on tropical cyclone climate projections. SOLA, 6 , 73-76.

Murakami, H., and B. Wang, 2010: Future change of North Atlantic tropical cyclone tracks: Projection by a 20-km-mesh global atmospheric model. J. Climate, 23, 2699-2721.

Murakami, H., B. Wang, and A. Kitoh, 2011: Future change of western North Pacific typhoons: Projections by a 20-km-mesh global atmospheric model. J. Climate, 24, 1154-1169.

Murakami, H., R. Mizuta, and E. Shindo, 2012a: Future changes in tropical cyclone activity projected by multi-physics and multi-SST ensemble experiments using the 60-km-mesh MRI-AGCM. Climate Dyn., 39, 2569-2584.

Murakami, H., Y. Wang, H. Yoshimura, R. Mizuta, M. Sugi, E. Shindo, Y. Adachi, S. Yukimoto, M. Hosaka, S. Kusunoki, T. Ose, and A. Kitoh, 2012b: Future changes in tropical cyclone activity projected by the new high-resolution MRI-AGCM. J. Climate, 25, 3237-3260.

Murakami, H., M. Sugi, and A. Kitoh, 2013a: Future changes in tropical cyclone activity in the North Indian Ocean projected by high resolution MRI-AGCMs. Climate Dyn., 40, 1949-1968.

Murakami, H., B. Wang, T. Li, and A. Kitoh, 2013b: Projected increase in tropical cyclones near Hawaii. Nat. Climate Change, 3, 749-754.

Murakami, H., T. Li, and P.-C. Hsu, 2014: Contributing factors to the recent high level of Accumulated Cyclone Energy (ACE) and Power Dissipation Index (PDI) in the North Atlantic. J. Climate, 27, 3023-3034.

Murata, A., M. Nakano, S. Kanada, K. Kurihara, and H. Sasaki, 2012: Summertime temperature extremes over Japan in the late 21 st-century climate projected by a high-resolution regional climate model. J. Meteor. Soc. Japan, 90A, 101-122.

Nakaegawa, T., and W. Vergara, 2010: First projection of climatological mean river discharges in the Magdalena River Basin, Colombia, in a changing climate during the 21 st century. Hydrol. Res. Lett., 4, 50-54.

Nakaegawa, T., A. Kitoh, Y. Ishizaki, S. Kusunoki, and H. Murakami, 2013: Caribbean low-level jets and accompanying moisture fluxes in a global warming climate projected with CMIP3 multi-model ensemble and fine-mesh atmospheric general circulation models. Int. J. Climatol., 34, 964-977.

Nakaegawa, T., A. Kitoh, H. Murakami, and S. Kusu- noki, 2014: Annual maximum 5-day rainfall total and maximum number of consecutive dry days over Central America and the Caribbean in the late twenty-first century projected by an atmospheric general circulation model with three different horizontal resolutions. Theor. Appl. Climatol., 116, 155-168.

Nakamura, M., S. Kanada, Y. Wakazuki, C. Muroi, A. Hashimoto, T. Kato, A. Noda, M. Yoshizaki, and K. Yasunaga, 2008: Effects of global warming on heavy rainfall during the Baiu season projected by a cloud-system-resolving model. J. Disaster Res., 3, 15-24.

Nakano, M., S. Kanada, and T. Kato, 2010: Statistical analysis of simulated direct and indirect precipitation associated with typhoons around Japan using a cloudsystem resolving model. Hydrol. Res. Lett., 4, 6-10.

Nakano, M., S. Kanada, T. Kato, and K. Kurihara, 2011: Monthly maximum number of consecutive dry days in Japan and its reproducibility by a 5-km-mesh cloud-system resolving regional climate model. Hydrol. Res. Lett., 5, 11-15.

Nakano, M., T. Kato, S. Hayashi, S. Kanada, Y. Yamada, and K. Kurihara, 2012: Development of a 5-km-mesh cloud-system-resolving regional climate model at the Meteorological Research Institute. J. Meteor. Soc. Japan, 90A, 339-360.

NPD/JMA, 2002: Outline of the operational numerical weather prediction of the Japan Meteorological Agency. Japan Meteorological Agency, 158 pp.

Oouchi, K., J. Yoshimura, H. Yoshimura, R. Mizuta, S. Kusunoki, and A. Noda, 2006: Tropical cyclone climatology in a global warming climate as simulated in a $20 \mathrm{~km}$-mesh global atmospheric model: frequency and wind intensity analyses. J. Meteor. Soc. Japan, 84, 259-276.

Pérez, E. P., V. Magaña, E. Caetano, and S. Kusunoki, 2014: Cold surge activity over the Gulf of Mexico in a warmer climate. Front. Earth Sci., 2, 19, doi:10.3389/ feart.2014.00019.

Rahman, M. M., N. Ferdousi, T. Sato, S. Kusunoki, and A. Kitoh, 2012: Rainfall and temperature scenario for Bangladesh using $20 \mathrm{~km}$ mesh AGCM. Int. J. Climate Change Strategies and Management, 4, 66-80.

Rahman, M. M., M. Rafiuddin, M. M. Alam, S. Kusunoki, A. Kitoh, and F. Giorgi, 2013: Summer monsoon rainfall scenario over Bangladesh using a high-resolution AGCM. Nat. Hazards, 69, 793-807.

Raible, C. C., S. Kleppek, M. Wuest, D. N. Bresch, A. Kitoh, H. Murakami, and T. F. Stocker, 2012: Atlantic hurricanes and associated insurance loss potentials in future climate scenarios. Tellus A, 64, 15672, doi:10.3402/tellusa.v64i0.15672.

Rajendran, K., and A. Kitoh, 2008: Indian summer monsoon in future climate projection by a super-high-resolution global model. Current Sci., 95, 1560-1569.

Rajendran, K., A. Kitoh, J. Srinivasan, R. Mizuta, and R. 
Krishnan, 2012: Monsoon circulation interaction with Western Ghats orography under changing climate: Projection by an ultra-high resolution global model. Theor. Appl. Climatol., 110, 555-571.

Rajendran, K., S. Sajani, C. B. Jayasankar, and A. Kitoh, 2013: How dependent is climate change projection of Indian summer monsoon rainfall and extreme events on model resolution? Current Sci., 104, 1409-1418.

Randall, D. A., and D. M. Pan, 1993: Implementation of the Arakawa-Schubert cumulus parameterization with a prognostic closure. The Representation of Cumulus Convection in Numerical Models of the Atmosphere. Meteor. Monog., 46, 137-147.

Sasaki, H., H. Kida, T. Koide, and M. Chiba, 1995: The performance of long-term integration of a limited area model with the spectral boundary coupling method. $J$. Meteor. Soc. Japan, 73, 165-181.

Sasaki, H., Y. Sato, K. Adachi, and H. Kida, 2000: Performance and evaluation of the MRI regional climate model with the spectral boundary coupling method. $J$. Meteor. Soc. Japan, 78, 477-489.

Sasaki, H., K. Kurihara, and I. Takayabu, 2005: Comparison of climatic reproducibility between a super-high-resolution atmosphere general circulation model and a Metrorological Research Institute regional climate model. SOLA, 1, 81-84.

Sasaki, H., K. Kurihara, I. Takayabu, K. Murazaki, Y. Sato, and H. Tsujino, 2006: Preliminary results from the coupled atmosphere-ocean regional climate model at the Meteorological Research Institute. J. Meteor. Soc. Japan, 84, 389-403.

Sasaki, H., A. Murata, M. Hanafusa, M. Oh'izumi, and K. Kurihara, 2012: Projection of future climate change in a non-hydrostatic regional climate model nested within an atmospheric general circulation model. SOLA, 8, 53-56.

Sato, T., F. Kimura, and A. Kitoh, 2007: Projection of global warming onto regional precipitation over Mongolia using a regional climate model. J. Hydrol., 333, 144-154.

Sato, Y., S. Yukimoto, H. Tsujino, H. Ishizaki, and A. Noda, 2006: Response of North Pacific ocean circulation in a Kuroshio-resolving ocean model to an Arctic Oscillation (AO)-like change in Northern Hemisphere atmospheric circulation due to greenhouse-gas forcing. J. Meteor. Soc. Japan, 84, 295-309.

Sugi, M., and J. Yoshimura, 2012: Decreasing trend of tropical cyclone frequency in 228-year high-resolution AGCM simulations. Geophys. Res. Lett., 39, L19805, doi:10.1029/2012GL053360.

Tsunematsu, N., K. Dairaku, and J. Hirano, 2013: Future changes in summertime precipitation amounts associated with topography in the Japanese islands. $J$. Geophys. Res., 118, 4142-4153.

van der Linden, P., and J. F. B. Mitchell, 2009: ENSEM-
BLES, Climate Change and its Impacts: Summary of research and results from the ENSEMBLES project. Met Office Hadley Centre, UK, 160 pp.

Wakazuki, Y., S. Kanada, C. Muroi, A. Hashimoto, T. Kato, M. Nakamura, A. Noda, M. Yoshizaki, and K. Yasunaga, 2007: Regional climate projection experiments on the Baiu frontal activity around the Japan Islands using a non-hydrostatic cloud-system-resolving model. J. Earth Simulator, 8, 13-25.

Wakazuki, Y., M. Hara, M. Fujita, X. Ma, and F. Kimura, 2013: Development of incremental dynamical downscaling and analysis system for regional scale climate change projections. EGU General Assembly Conference Abstracts, 15, 13442-13442.

Wang, B., Q. Ding, X. Fu, I.-S. Kang, K. Jin, J. Shukla, and F. Doblas-Reyes, 2005: Fundamental challenge in simulation and prediction of summer monsoon rainfall. Geophys. Res. Lett., 32, L15711, doi:10.1029/2005GL022734.

Wang, B., H.-J. Kim, K. Kikuchi, and A. Kitoh, 2011: Diagnostic metrics for evaluation of annual and diurnal cycles. Climate Dyn., 37, 941-955.

$\mathrm{Xu}, \mathrm{Z}$., and Z.-L. Yang, 2012: An improved dynamical downscaling method with GCM bias corrections and its validation with 30 years of climate simulations. $J$. Climate, 25, 6271-6286.

Yoshimura, K., and M. Kanamitsu, 2013: Incremental correction for the dynamical downscaling of ensemble mean atmospheric fields. Mon. Wea. Rev., 141, 3087-3101.

Yoshimura, H., R. Mizuta, and H. Murakami, 2015: A spectral cumulus parameterization scheme interpolating between two convective updrafts with Semi-Lagrangian calculation of transport by compensatory subsidence. Mon. Rev. Rev., 143, 597-621.

Yukimoto, S., A. Noda, A. Kitoh, M. Sugi, Y. Kitamura, M. Hosaka, K. Shibata, S. Maeda and T. Uchiyama, 2001: A new meteorological research institute coupled GCM (MRI-CGCM2) - Model climate and its variability-. Pap. Meteor. Geophys., 51, 47-88.

Yukimoto, S., A. Noda, A. Kitoh, M. Hosaka, H. Yoshimura, T. Uchiyama, K. Shibata, O. Arakawa, and S. Kusunoki, 2006: Present-day climate and climate sensitivity in the Meteorological Research Institute coupled GCM version 2.3 (MRI-CGCM2.3). J. Meteor. Soc. Japan, 84, 333-363.

Yun, K.-S., S.-H. Shin, K.-J. Ha, A. Kitoh, and S. Kusunoki, 2008: East Asian precipitation change in the global warming climate simulated by a $20-\mathrm{km}$ mesh AGCM. Asia-Pacific J. Atmos. Sci., 44, 233-247.

Yun, K.-S., K.-Y. Heo, J.-E. Chu, K.-J. Ha, E.-J. Lee, Y. Choi, and A. Kitoh, 2012: Changes in climate classification and extreme climate indices from a high-resolution future projection in Korea. Asia-Pacific $J$. Atmos. Sci., 48, 213-226. 